\title{
Assessment of retention basin volume and outlet capacity in urban stormwater drainage systems with respect to water quality
}

\author{
MEHMET A YURDUSEV ${ }^{1}$, AHMET A KUMANLIOĞLU ${ }^{2}$ and \\ BEKIR SOLMAZ ${ }^{1}$
}

${ }^{1}$ Celal Bayar Univesity, Civil Engineering Department, Muradiye, Manisa, Turkey ${ }^{2}$ Dokuz Eylül University, Civil Engineering Department, Kaynaklar Campus, Buca, İzmir, Turkey

e-mail: yurdusev@bayar.edu.tr

MS received 8 March 2005; revised 19 July 2005

\begin{abstract}
The quality of river water or other surface waters is detrimentally affected by the contaminants carried by the rainfall runoff in urban areas. The control of pollution moved by rainfall runoff is achieved by installing outlets and small retention basins in stormwater collection systems, thereby allowing only a certain amount of rainfall water to overflow and leading the remaining to treatment plants. This study analyses the effect of concentration time on surface water pollution caused by rainfall runoff. For this purpose, a linear S-curve is assumed for the flow hydrograph arising from the collection system, based on parameters of rainfall considered and the catchment area. An independent code is developed to analyse such a system and this is applied to an urban area using nine-year single-discrete rainfall records of Izmir Station, Turkey. The system is capable of tackling situations where there is only a basin or a basin with outlet.
\end{abstract}

Keywords. Stormwater drainage system; retention basin; outlet capacity; water quality.

\section{Introduction}

Stormwater drainage system design is being revisited although it has quite a long history. This is partly because of frightening heavy rainfall events experienced in many parts of the world recently. Another reason is that quality considerations have become much more important than before, as cities are becoming larger by the day. Research into better design practices have been conducted in an attempt to sustain the system. One way to tackle the large amounts of stormwater is to install temporary stormwater catchments (Piel et al 1999). In urban areas, the runoff caused by heavy rainfall moves a lot of contaminants to the final recipient surface water bodies such as rivers, lakes or even the sea. This is one of the big challenges that city managers face and various ways of tackling it have been investigated (Bourgogne \& Chorda 1995). 
The level of contaminants transported from the cities to such water bodies is monitored by installing small retention basins in stormwater drain systems connected to the outlets. The idea here is to allow some amount of rain water to overflow from the outlets and the rest to be led either to treatment plants or to a receiving media directly if the quality is acceptable (Annen \& Londong 1960; Muslu 1966). It is aimed in such system operation that the amount of contaminants transported by the water overflowing from the outlet to the recipient water media should not exceed acceptable limits. To achieve this purpose the water volume passing over the outlet should be determined. The quality parameters of stormwater will then help to determine

- the organic material load moved into surface waters

- its duration or lifetime

- its frequency.

The input to such a system is the flow hydrograph of rainfall runoff in the collection system. The hydrograph is based on the function of rainfall intensity, rainfall duration and characteristics of the drainage area. Clearly, such a system is rather complicated and its analysis will require some simplifications. To this end, an independent code is developed to analyse such a system in this research work. The system is applied to an urban area using nine-year single discrete rainfall data with the single linear S-curve assumption (Ordon 1974).

\section{Assessment of retention basins in with linear S-curve}

There are two different situations where a rainfall runoff hydrograph is obtained. These can be distinguished based on whether the rainfall duration $\left(t_{d}\right)$ is less than concentration time $\left(t_{c}\right)$. As such, the retention basin problem can be solved by considering these situations separately as in the following sections.

\subsection{Assessment of overflow duration for $t_{d}>t_{c}$}

There generally exists a retention basin run in association with an outlet allowing the excess water to overflow freely. Denoting the rainfall yield as $r_{c r}$ when the overflow starts, the discharge from the drainage area can be expressed as,

$$
Q_{c r}=r_{c r} \sum c_{n} A_{n},
$$

where $c_{n}$ is the flow efficiency related to the $n$th part of the drainage area, $A_{n}$.

Runoff values equal to or less than $Q_{c r}$ are conveyed to a treatment plant or the final discharge point without pre-treatment as illustrated in figure 1 .

If the runoff is higher than $Q_{c r}$, the excess water $\left(Q-Q_{c r}\right)$ overflows from the outlet and is then stored in the retention basin. The runoff hydrograph for the case $t_{d}>t_{c}$ is shown in figure 2. Given the time period $\left(T_{b}\right)$ elapsing from the beginning of the rainfall until the basin

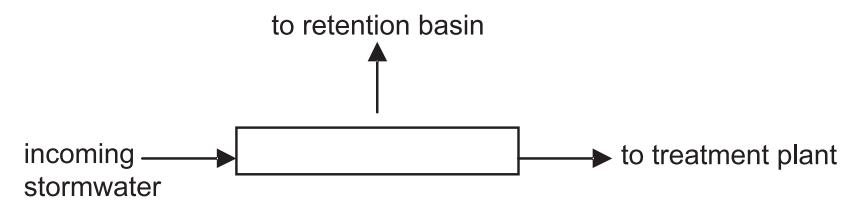

Figure 1. Flow relations in a retention basin system. 


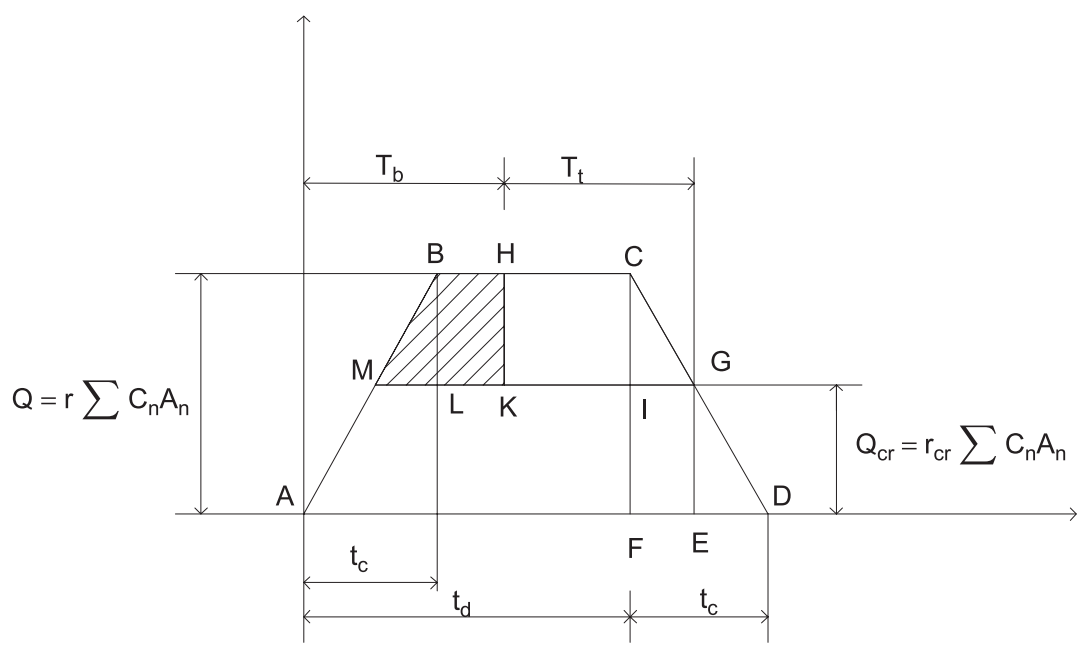

Figure 2. Flow hydrograph for $t_{d}>t_{c}$.

fills up; the shaded area in figure 2 shows the amount of water stored in this period $\left(V_{b}\right)$, which represents the volume of the basin. The amount of overflowing water from the time when the basin is full until the runoff is less than $Q_{c}$, is disposed off by the recipient water body though a flood channel.

Denoting the rainfall yield by $r$, when $r_{c r}>r$, there is no overflow whether a retention basin has been installed or not. However, when $r_{c r}<r$ and $V_{t}>0$, overflow occurs with duration $T_{t}$. If $n$ is an integer, taking the value of 1 for a particular spell of rain if there is overflow and 0 otherwise, total overflow number $\left(\sum n_{i}\right.$ if $\left.n_{i}=1\right)$, total overflow time $\left(\sum T_{t}\right)$ and total overflowing water volume $\left(\sum V_{t}\right)$ can be calculated for the rainfall data of a certain rainfall-gauge station. Given $t_{c}, \sum c_{n} A_{n}$ and $r_{c r}$, the overflowing water volume, $V_{t}$, from a basin with a volume of $V_{b}$ and overflow duration, $T_{t}$, resulting from the spell of rain with duration of $t_{d}$ and height $P$ can be easily calculated using the geometrical properties (figure 2).

To express the results in general form, the volumes $V_{b}$ and $V_{t}$ can be re-formulated based on water height. The volume of the basin is, therefore, written as,

$$
V_{b}=\left(\bar{V}_{b} / 10^{3}\right) \sum c_{n} A_{n} 10^{4}=\bar{V}_{b} \sum c_{n} A_{n} 10,
$$

where $\bar{V}_{b}$ is the equivalent water height for the volume $V_{b}$, which is uniformly distributed over the drainage area, $\sum c_{n} A_{n}$. It should be noted that the units used in (2) follow $A_{n}$ (ha), $V_{b}\left(\mathrm{~m}^{3}\right), r$ (lt/sn ha) and $\bar{V}_{b}(\mathrm{~mm})$. Similarly, the overflowing water volume, $V_{t}$ in $\mathrm{m}^{3}$ can be expressed as equivalent water height for the volume $V_{t}$ in $\mathrm{mm}$,

$$
V_{t}=\left(\bar{V}_{t} / 10^{3}\right) \sum c_{n} A_{n} 10^{4}=\bar{V}_{t} \sum c_{n} A_{n} 10 .
$$

From figure 2 , the filling-up $\left(T_{p}\right)$ and overflow $\left(T_{t}\right)$ durations can be written as

$$
\begin{aligned}
T_{b} & =t_{c}+\frac{\bar{V}_{b}}{\left[\left(r-r_{c r}\right) / 166 \cdot 74\right]}-\frac{t_{c}}{2}\left(1-\frac{r_{c r}}{r}\right), \\
T_{t} & =t_{d}-\frac{3}{2} t_{c} \frac{r_{c r}}{r}-\frac{\bar{V}_{b}}{\left[\left(r-r_{c r}\right) / 166 \cdot 74\right]}+\frac{t_{c}}{2} .
\end{aligned}
$$


Equation (5) is applicable provided $t_{d}>0$ and the distance between the points $\mathrm{B}$ and $\mathrm{H}(\overline{B H})$ in figure 2 is greater than 0 . The durations given in (4) and (5) are minutes and this applies to the generalizations used later on as well.

2.1a Special cases in assessing overflow duration for $t_{d}>t_{c}$ : There are three cases which should be given special attention in calculating overflow durations when $t_{d}>t_{c}$ as follows:

- $r_{c r}=r$ and $\bar{V}_{b} \neq 0$,

- $r_{c r}=r$ and $\bar{V}_{b}=0$, and

- the volume of the basin is very small.

These cases are examined independently as follows.

(1) $r_{c r}=r$ and $\bar{V}_{b} \neq 0$ : In this case, the overflowing water volume is infinitely small and therefore, it can be assumed that there is no overflow $\left(n_{i}=0\right)$. In this case, $V_{t}$ and $T_{t}$ cannot be calculated, since $\bar{V}_{b} \neq 0$, the shaded area covers the whole area over $Q_{c r}$ line in figure 2 in the limit case, thereby $\lim _{r_{c r} \rightarrow r}\left(T_{t}\right)=0$.

(2) $r_{c r}=r$ and $\bar{V}_{b}=0$ : The overflowing water volume is also infinitely small in this case thereby producing no overflow $\left(n_{i}=0\right)$. Since there is no basin, the shaded area in figure 2 does not exist. In the limit case, from (5), it can easily be seen that $\lim _{r_{c r} \rightarrow r}\left(T_{t}\right)=t_{d}-t_{c}$.

(3) Small basin case: From figure 2 the distance between the points $\mathrm{B}$ and $\mathrm{H}(\overline{B H})$ can be obtained as

$$
\overline{B H}=\frac{\bar{V}_{b}}{\left[\left(r-r_{c r}\right) / 166 \cdot 74\right]}-\frac{t_{c}}{2}\left(1-\frac{r_{c r}}{r}\right) \leq 0 .
$$

In this case the following inequality can be observed;

$$
V_{b} \leq\left(t_{c} / 2 r\right)\left[\left(r-r_{c r}\right)^{2} / 166 \cdot 7\right] .
$$

The area from which the basin volume is calculated is less than that of the triangle MBL. This means that figure 2 is no longer applicable to this case, and figure 3 may be used to illustrate it instead. Durations of $T_{b}$ and $T_{t}$ given in (4) and (5) should be reformulated using figure 3 as follows;

$$
\begin{aligned}
& T_{b}=t_{c}\left(r_{c r} / r\right)+\left(333.4 V_{b} t_{c} / r\right)^{1 / 2} \\
& T_{t}=t_{d}+t_{c}-2 t_{c}\left(r_{c r} / r\right)+\left(333.4 V_{b} t_{c} / r\right)^{1 / 2} .
\end{aligned}
$$

2.1b Assessment of overflow volume for $t_{d}>t_{c}$ : When $t_{d}>t_{c}$, the overflowing water volume can be obtained by subtracting the volume $\bar{V}_{b}$ from the volume represented by the area MBCG in figure 3 as follows;

$$
V_{t}=P-\left(r_{c r} / 166 \cdot 7\right)\left(t_{d}+t_{c}-t_{c}\left(r_{c r} / r\right)\right)-\bar{V}_{b} .
$$

There are also special cases in calculating overflow volume for $t_{d}>t_{c}$ as follows;

- $r_{c r}=r$ and $\bar{V}_{b} \neq 0$,

- $r_{c r}=r$ and $\bar{V}_{b}=0$,

- the basin is small. 


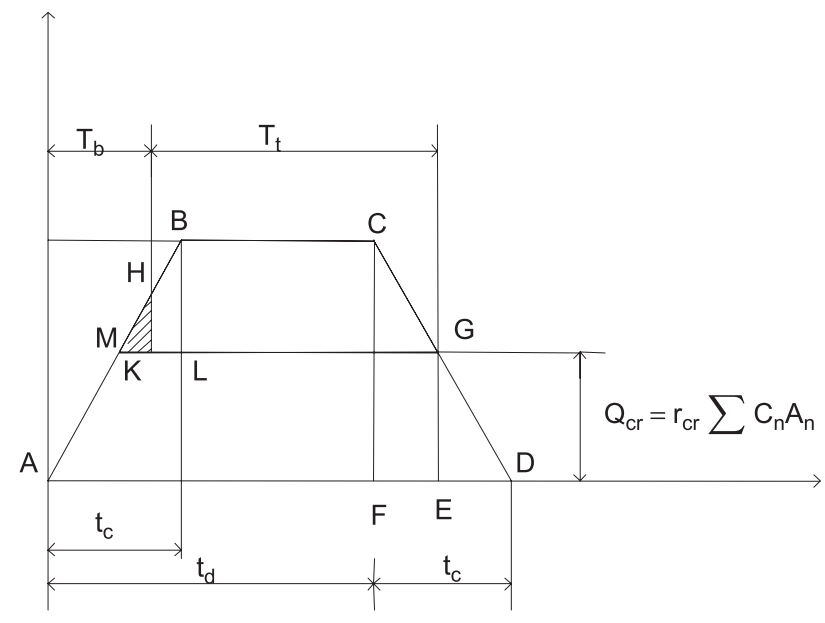

Figure 3. Flow hydrograph for $t_{d}>t_{c}$ for small basin case.

For the first two cases, $n_{i}=0$ and therefore no overflow takes place, whereas for the last case (figure $2, \overline{B H}<0$ ), the equations can be obtained in the same way as previously mentioned. Therefore, (9) also applies to this case.

\subsection{The assessment of overflow duration for $t_{d}<t_{c}$}

This case is illustrated in figure 4 . The following expressions for $T_{b}$ and $T_{t}$ can be written from triangle CFD in figure 4 as,

$$
\begin{aligned}
T_{b} & =t_{d}+166 \cdot 7 \frac{\bar{V}_{b} t_{c}}{t_{d} r-t_{c} r_{c r}}-\frac{t_{d} r-t_{c} r_{c r}}{2 r}, \\
T_{t} & =\frac{t_{d}}{2}-\frac{3}{2} t_{c} \frac{r_{c r}}{r}-166 \cdot 7 \frac{\bar{V}_{b}}{r\left(t_{d} / t_{c}\right)-r_{c r}}+t_{c} .
\end{aligned}
$$

There are three possible special cases that can be encountered during the calculation of $T_{b}$ and $T_{t}$. These are dealt with in the following section.

2.2a Special cases: (1) $r_{c r}=\frac{t_{d}}{t_{c}} r$ and $\bar{V}_{b} \neq 0$ : In this case, there is no overflow (e.g. $\left.n_{i}=0\right)$ and the following can be written for $T_{t} \lim \left(T_{t}\right)=0$.

(2) $r_{c r}=\left(t_{d} / t_{c}\right) r$ and $\bar{V}_{b}=0$ : No overflow takes place in this case $\left(n_{i}=0\right)$ also and taking the limit of (11) yields

$$
\lim _{r_{c r} \rightarrow\left(t_{d} / t_{c}\right) r}\left(T_{t}\right)=\frac{t_{d}}{2}-t_{d}
$$

(3) Small basin case: From figure $4, \overline{B H}$ can be obtained as

$$
\overline{B H}=\frac{\bar{V}_{b} t_{c}}{\left(t_{d} r-t_{c} r_{c r}\right) / 166 \cdot 7}-\frac{t_{d} r-t_{c} r_{c r}}{2 r} \leq 0 .
$$




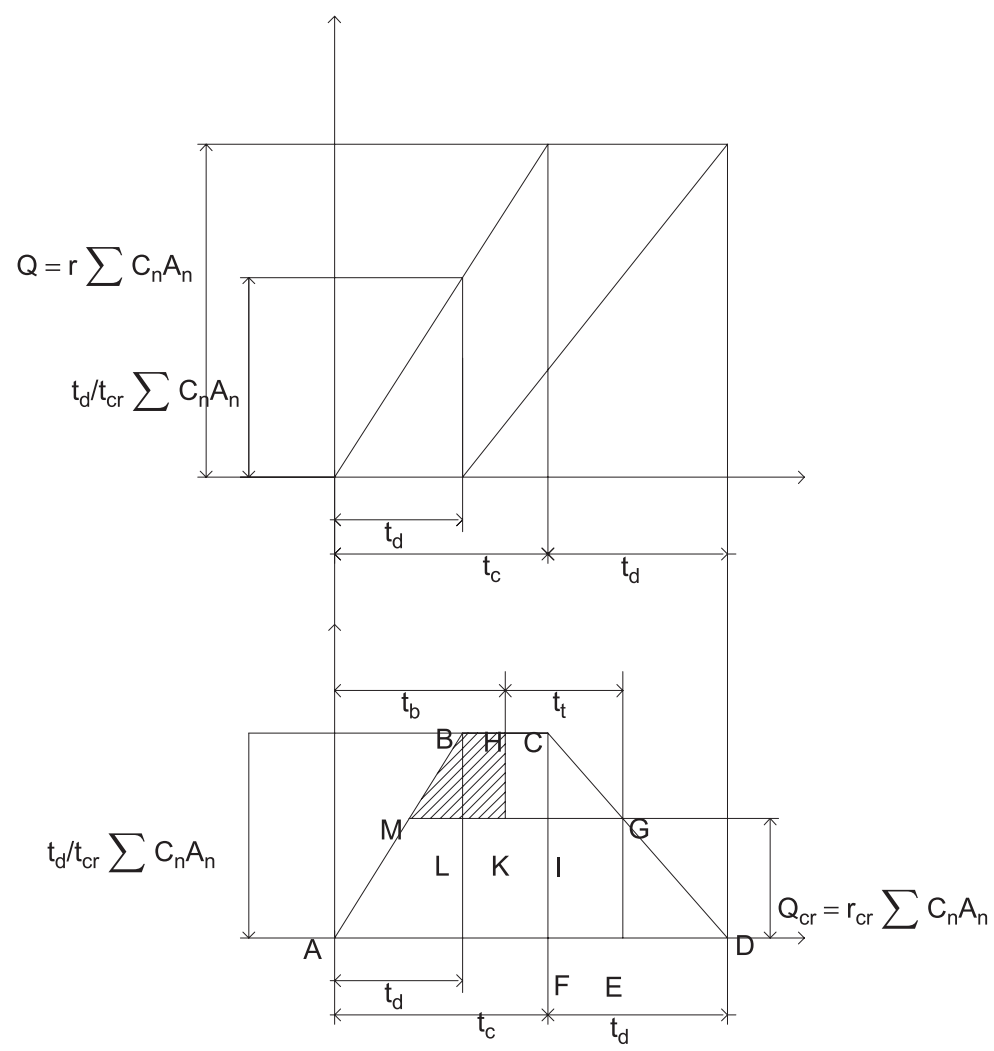

Figure 4. Flow hydrograph for $t_{d}<t_{c}$.

In this case, the inequality

$$
\bar{V}_{b} \leq\left(t_{d} r-t_{c} r_{c r}\right)^{2} / 333.4 r t_{c},
$$

should apply and therefore it is no longer possible to use figure 4. Alternatively, the illustrations given in figure 5 can be used. From figure 5, the fill-up and overflow durations can be as follows,

$$
\begin{aligned}
& T_{b}=t_{c}\left(r_{c r} / r\right)+\left(333 \cdot 4 \bar{V}_{b} t_{c} / r\right)^{1 / 2}, \\
& T_{t}=t_{c}+t_{d}-2 t_{c}\left(r_{c r} / r\right)+\left(333.4 \bar{V}_{b} t_{c} / r\right)^{1 / 2} .
\end{aligned}
$$

2.2b The assessment of overflow volume for $t_{d}<t_{c}$ : Basin volume can be obtained by subtracting the volume $V_{b}$ from the volume represented by MBCG. This takes the same form as that in (9) obtained using figure 4.

\section{Model development for retention basin design}

From the theoretical explanations given previously, it can easily be seen that systematic calculations cannot be done manually and a special code is required. Considering the necessity 


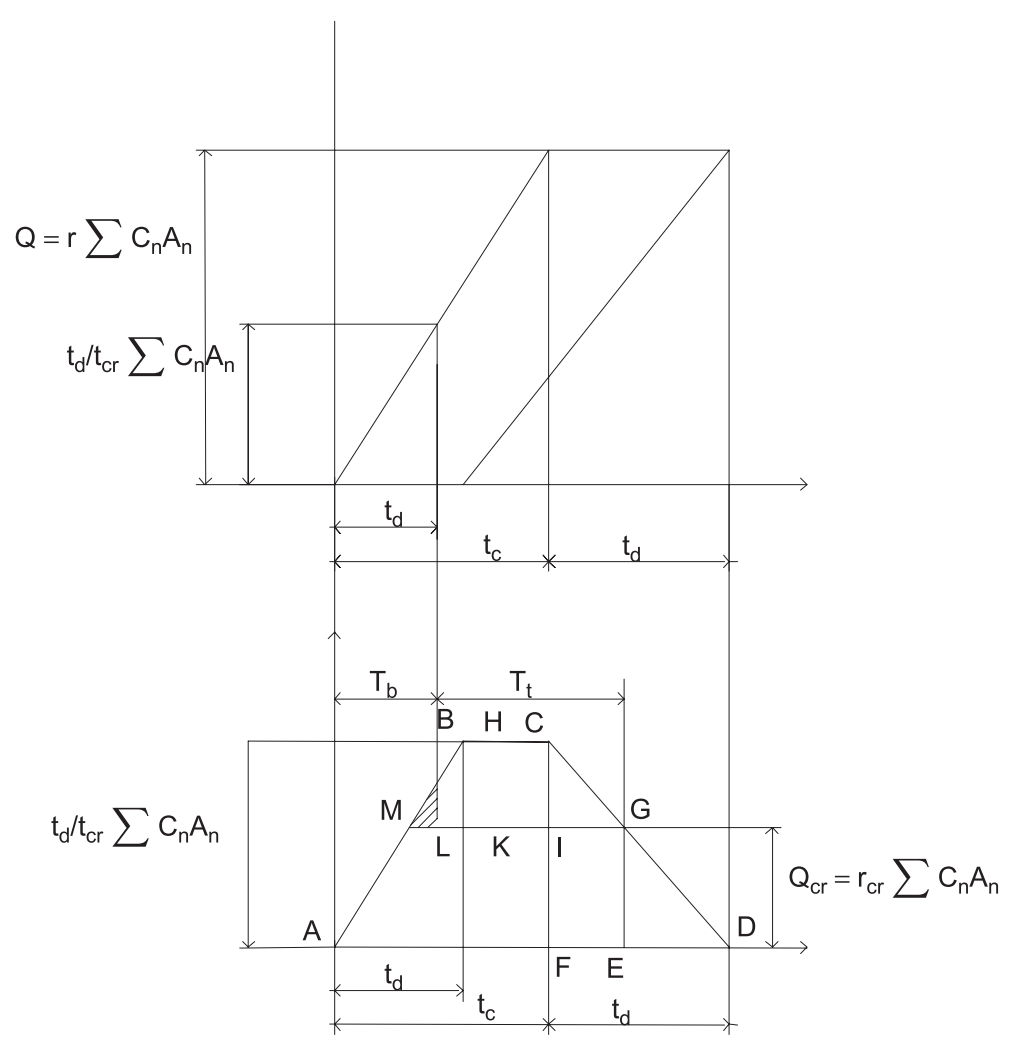

Figure 5. Flow hydrograph for $t_{d}<t_{c}$ for small basin case.

of making calculations with the large amount of data to monitor the system performance, computer-based analysis is inevitable. To this end, a special code has been developed for systematic calculations. The general structure of the model developed is given in figure 6 . As seen from the figure, the model first calculates the overflow durations, overflow heights and overflow numbers for a selected basin volume from the data supplied to the model through data files. The program then assesses the overflow characteristics. The process continues until the prescribed maximum basin volume is exceeded. The model finally presents the overflow characteristics in output files. Using such a model, it is possible to undertake such calculations using the observations or even the synthetic data to check every situation. It is therefore possible to test a retention basin system in urban storm sever systems.

\section{Case study}

Having developed a model for the design of retention basins in urban storm sewer systems, the model has been applied to 3-year single-discrete rainfall data observed at the Izmir rainfallgauge station in Turkey between 1977 and 1980. The results are standardized by dividing them into the maximum values obtained for the cases $r_{c r}=0$ and $\bar{V}_{b}=0$ in an attempt to generalize them and to uncover the effect of collection time on the results, which are presented in tables 1,2 and 3. Table 1 gives standardized values which are used for assessing overflow heights for 


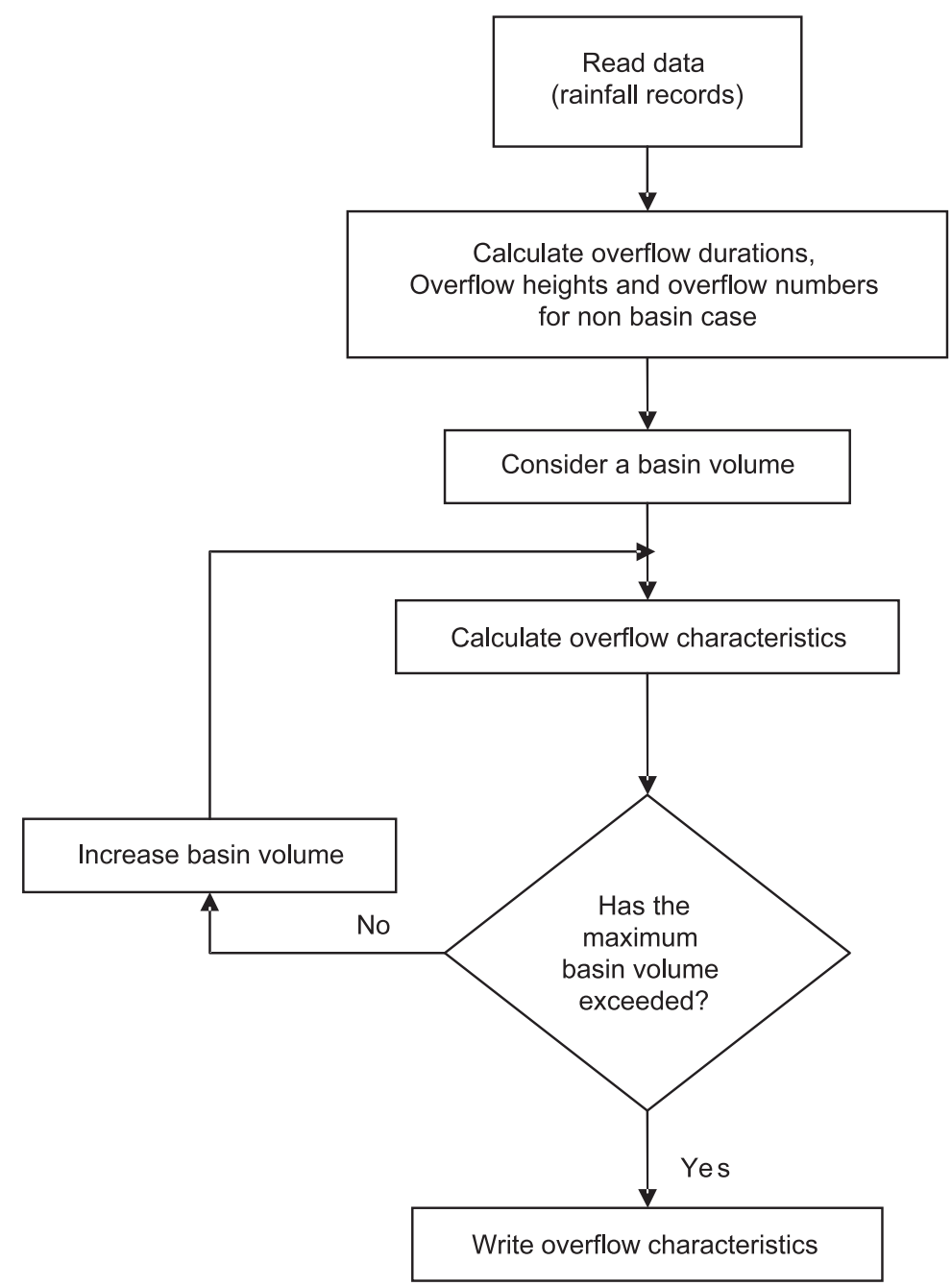

Figure 6. General structure of the model developed.

a given basin volume (e.g. $\bar{V}_{b}$ ) as a function of $r_{c r}$ and concentration time. Similarly table 2 gives dimensionless numbers for overflow numbers and table 3 for overflow durations. The use of the procedure and the model introduced in this study are explained in the following example calculation for overflow duration and therefore the contaminant load flowing from the stormwater drainage system to the recipient water body.

Given an urban area of population density 200 person/ha, water consumption in litres per person $(q)$ is $200 \mathrm{l} / \mathrm{per}$ day, flow coefficient $\left(C_{n}\right)$ is $0 \cdot 46$, the total area $\left(A_{n}\right)$ is $50 \mathrm{ha}$, and the maximum rainfall value in a 5-year period $\left(P_{y}\right)$ is $1005.6 \mathrm{~mm}$. The overflow duration has to be calculated, assuming that the biological oxygen demand (BOD) is $100 \mathrm{mg} / \mathrm{l}$ for overflowing urban stormwater and the concentration time is 30 minutes.

Since the overflow durations in figure 6 are standardized, the first thing to do is to obtain the real value $\left(T_{t}\right)_{\max }$. To do that, the total annual discrete rainfall duration is required. This value 
Table 1. The dimensionless values used in calculating overflow heights.

\begin{tabular}{|c|c|c|c|c|c|}
\hline \multirow{2}{*}{$\begin{array}{l}r_{c r} \\
(1 / \mathrm{s} \text { ha })\end{array}$} & \multirow{2}{*}{$\begin{array}{c}V_{b} \\
(\mathrm{~mm})\end{array}$} & \multicolumn{4}{|c|}{ Concentration time, $t_{c}$ (min.) } \\
\hline & & 0 & 10 & 30 & 50 \\
\hline \multirow[t]{6}{*}{0} & $0 \cdot 0$ & 1.000 & 1.000 & 1.000 & 1.000 \\
\hline & $1 \cdot 0$ & 0.640 & 0.640 & 0.640 & 0.640 \\
\hline & $5 \cdot 0$ & $0 \cdot 194$ & $0 \cdot 194$ & 0.194 & 0.194 \\
\hline & $10 \cdot 0$ & $0 \cdot 081$ & $0 \cdot 081$ & 0.081 & $0 \cdot 081$ \\
\hline & $15 \cdot 0$ & 0.025 & 0.025 & 0.025 & 0.025 \\
\hline & $20 \cdot 0$ & 0.016 & $0 \cdot 016$ & $0 \cdot 016$ & 0.016 \\
\hline \multirow[t]{6}{*}{0.5} & $0 \cdot 0$ & 0.998 & 0.998 & 0.995 & 0.973 \\
\hline & $1 \cdot 0$ & 0.613 & $0 \cdot 610$ & 0.595 & 0.577 \\
\hline & $5 \cdot 0$ & $0 \cdot 187$ & $0 \cdot 187$ & $0 \cdot 182$ & 0.182 \\
\hline & $10 \cdot 0$ & 0.072 & 0.072 & 0.072 & 0.070 \\
\hline & $15 \cdot 0$ & 0.023 & 0.023 & 0.023 & 0.023 \\
\hline & $20 \cdot 0$ & $0 \cdot 016$ & $0 \cdot 016$ & $0 \cdot 016$ & 0.023 \\
\hline \multirow[t]{6}{*}{1} & 0.0 & 0.971 & 0.971 & 0.959 & 0.881 \\
\hline & 1.0 & 0.583 & 0.565 & 0.538 & 0.516 \\
\hline & $5 \cdot 0$ & 0.176 & 0.176 & 0.173 & 0.171 \\
\hline & $10 \cdot 0$ & 0.065 & 0.065 & 0.065 & 0.065 \\
\hline & $15 \cdot 0$ & 0.023 & 0.023 & 0.023 & 0.023 \\
\hline & $20 \cdot 0$ & $0 \cdot 014$ & 0.014 & 0.014 & 0.014 \\
\hline \multirow[t]{6}{*}{5} & $0 \cdot 0$ & 0.523 & 0.523 & 0.482 & 0.403 \\
\hline & $1 \cdot 0$ & 0.293 & $0 \cdot 279$ & $0 \cdot 261$ & 0.236 \\
\hline & $5 \cdot 0$ & 0.081 & 0.079 & 0.077 & 0.070 \\
\hline & $10 \cdot 0$ & 0.029 & 0.027 & 0.023 & 0.023 \\
\hline & $15 \cdot 0$ & $0 \cdot 014$ & $0 \cdot 014$ & $0 \cdot 014$ & $0 \cdot 014$ \\
\hline & $20 \cdot 0$ & 0.009 & 0.009 & 0.009 & 0.009 \\
\hline \multirow[t]{6}{*}{10} & $0 \cdot 0$ & $0 \cdot 234$ & $0 \cdot 234$ & $0 \cdot 196$ & $0 \cdot 164$ \\
\hline & 1.0 & $0 \cdot 137$ & $0 \cdot 133$ & 0.119 & $0 \cdot 101$ \\
\hline & $5 \cdot 0$ & $0 \cdot 047$ & $0 \cdot 045$ & 0.036 & 0.025 \\
\hline & $10 \cdot 0$ & 0.009 & $0 \cdot 009$ & 0.009 & 0.009 \\
\hline & $15 \cdot 0$ & 0.009 & $0 \cdot 009$ & 0.009 & 0.009 \\
\hline & $20 \cdot 0$ & 0.007 & 0.007 & 0.005 & 0.005 \\
\hline
\end{tabular}

is $33140 \mathrm{~min} /$ year or $33140 / 60=553$ hours/year. The number of discrete rainfall episodes recorded during the recording period is 444 . Therefore, the value of $\left(T_{t}\right)_{\max }$ is then calculated as,

$$
\begin{aligned}
\sum\left(T_{t}\right)_{\max } & =\sum t_{d}+n_{y} t_{c}=552+444(30 / 60) \\
& =774 \text { hours/year }(46440 \mathrm{~min} / \text { year }) .
\end{aligned}
$$

From table 3 , the value of $y_{n}$ is $3.8 \%$ for $r_{c r}=10 \mathrm{l} / \mathrm{s}$ ha and $t_{c}=30 \mathrm{~mm}$, the overflow duration for a year is $\sum T_{t}=0.145 \times 774=112.2$ hours/year. Similarly, $y_{p}$ is $8.4 \%$ from 
Table 2. The dimensionless values used in calculating overflow durations.

\begin{tabular}{|c|c|c|c|c|c|}
\hline \multirow{2}{*}{$\begin{array}{l}r_{c r} \\
(1 / \mathrm{s} \mathrm{ha})\end{array}$} & \multirow{2}{*}{$\begin{array}{c}V_{b} \\
(\mathrm{~mm})\end{array}$} & \multicolumn{4}{|c|}{ Concentration time, $t_{c}$ (min.) } \\
\hline & & 0 & 10 & 30 & 50 \\
\hline \multirow[t]{6}{*}{0} & $0 \cdot 0$ & 1.000 & 1.000 & 1.000 & 1.000 \\
\hline & $1 \cdot 0$ & 0.597 & 0.563 & 0.517 & 0.487 \\
\hline & $5 \cdot 0$ & 0.185 & $0 \cdot 174$ & $0 \cdot 160$ & $0 \cdot 150$ \\
\hline & $10 \cdot 0$ & 0.063 & 0.061 & 0.057 & 0.054 \\
\hline & $15 \cdot 0$ & $0 \cdot 021$ & 0.020 & 0.019 & 0.018 \\
\hline & $20 \cdot 0$ & $0 \cdot 010$ & $0 \cdot 010$ & $0 \cdot 010$ & 0.009 \\
\hline \multirow{6}{*}{0.5} & $0 \cdot 0$ & 0.999 & 0.966 & 0.919 & 0.884 \\
\hline & $1 \cdot 0$ & 0.561 & 0.522 & 0.466 & 0.426 \\
\hline & $5 \cdot 0$ & $0 \cdot 171$ & $0 \cdot 161$ & $0 \cdot 144$ & $0 \cdot 134$ \\
\hline & $10 \cdot 0$ & 0.056 & 0.053 & $0 \cdot 049$ & 0.046 \\
\hline & $15 \cdot 0$ & 0.020 & 0.019 & 0.017 & 0.016 \\
\hline & $20 \cdot 0$ & 0.009 & 0.009 & 0.009 & 0.008 \\
\hline \multirow[t]{6}{*}{1} & $0 \cdot 0$ & 0.982 & 0.923 & 0.838 & 0.769 \\
\hline & 1.0 & 0.524 & 0.481 & 0.418 & 0.374 \\
\hline & $5 \cdot 0$ & 0.158 & $0 \cdot 147$ & 0.131 & $0 \cdot 123$ \\
\hline & $10 \cdot 0$ & 0.049 & 0.046 & 0.042 & 0.040 \\
\hline & $15 \cdot 0$ & $0 \cdot 019$ & 0.018 & 0.016 & 0.015 \\
\hline & $20 \cdot 0$ & 0.008 & $0 \cdot 008$ & 0.007 & 0.007 \\
\hline \multirow[t]{6}{*}{5} & $0 \cdot 0$ & 0.572 & 0.499 & 0.393 & $0 \cdot 314$ \\
\hline & $1 \cdot 0$ & 0.278 & $0 \cdot 240$ & $0 \cdot 188$ & $0 \cdot 152$ \\
\hline & $5 \cdot 0$ & 0.069 & 0.062 & 0.051 & 0.043 \\
\hline & $10 \cdot 0$ & 0.021 & 0.019 & $0 \cdot 016$ & 0.014 \\
\hline & $15 \cdot 0$ & 0.007 & 0.006 & 0.006 & 0.005 \\
\hline & $20 \cdot 0$ & 0.004 & 0.004 & 0.004 & 0.003 \\
\hline \multirow[t]{6}{*}{10} & $0 \cdot 0$ & 0.231 & $0 \cdot 195$ & 0.143 & $0 \cdot 111$ \\
\hline & $1 \cdot 0$ & $0 \cdot 119$ & $0 \cdot 101$ & 0.074 & 0.056 \\
\hline & $5 \cdot 0$ & 0.023 & $0 \cdot 019$ & $0 \cdot 014$ & $0 \cdot 011$ \\
\hline & $10 \cdot 0$ & 0.007 & 0.007 & 0.006 & $0 \cdot 005$ \\
\hline & $15 \cdot 0$ & 0.005 & 0.004 & 0.004 & 0.004 \\
\hline & $20 \cdot 0$ & 0.003 & 0.003 & 0.002 & 0.002 \\
\hline
\end{tabular}

table 1, the overflowing water height becomes $\sum V_{t}=0.119 \times 1005.6=119.7 \mathrm{~mm}$ or $\sum V_{t}=0.46 \times 119.7 \times 30 \times 10=16519 \mathrm{~m}^{3} /$ year. The organic material load arising from this amount then becomes $16519 \times 0 \cdot 1=1651.9 \mathrm{~kg} / \mathrm{BOD}$ year. Considering a retention basin as storing a $5-\mathrm{mm}$ height of water in cubic metred, the volume of the basin can be determined, $V b=0.46 \times 30 \times 10 \times 5=690 \mathrm{~m}^{3} \cdot y_{p}$ and $y_{t}$ values are taken as 0.025 and 0.011 respectively from tables 1 and 2 for $r_{c r}=10 \mathrm{l} / \mathrm{s} \mathrm{ha}$ and $t_{c}=30 \mathrm{~min}$. The overflowing water quantity becomes $\sum V_{t}=0.025 \times 1005.6=25.1 \mathrm{~mm}$ or $\sum V_{t}=0.46 \times 30 \times 25.1 \times 10=$ $3464 \mathrm{~m}^{3} /$ year. Accordingly, the organic material load becomes $346.4 \mathrm{~kg} / \mathrm{BOD}$ year, which is less than half of that obtained in the no-basin case. Similarly overflow duration reduces to the value of $\sum T_{t}=0.011 \times 774=8.5$ hours/year (Solmaz 1982). 
Table 3. The dimensionless values used in calculating overflow numbers.

\begin{tabular}{|c|c|c|c|c|c|}
\hline \multirow{2}{*}{$\begin{array}{l}r_{c r} \\
(1 / \mathrm{s} \mathrm{ha})\end{array}$} & \multirow{2}{*}{$\begin{array}{c}V_{b} \\
(\mathrm{~mm})\end{array}$} & \multicolumn{4}{|c|}{ Concentration time, $t_{c}$ (min.) } \\
\hline & & 0 & 10 & 30 & 50 \\
\hline \multirow[t]{6}{*}{0} & 0.0 & 1.000 & 1.000 & 1.000 & 1.000 \\
\hline & 1.0 & 0.759 & 0.759 & 0.759 & 0.759 \\
\hline & $5 \cdot 0$ & 0.337 & 0.337 & $0 \cdot 337$ & 0.337 \\
\hline & $10 \cdot 0$ & 0.152 & $0 \cdot 152$ & $0 \cdot 152$ & $0 \cdot 152$ \\
\hline & $15 \cdot 0$ & 0.078 & 0.078 & 0.078 & 0.078 \\
\hline & $20 \cdot 0$ & $0 \cdot 048$ & $0 \cdot 048$ & $0 \cdot 048$ & $0 \cdot 048$ \\
\hline \multirow[t]{6}{*}{0.5} & 0.0 & 0.934 & 0.927 & 0.912 & 0.897 \\
\hline & 1.0 & 0.705 & 0.700 & 0.690 & 0.681 \\
\hline & $5 \cdot 0$ & $0 \cdot 311$ & $0 \cdot 310$ & $0 \cdot 307$ & $0 \cdot 304$ \\
\hline & $10 \cdot 0$ & $0 \cdot 139$ & $0 \cdot 139$ & $0 \cdot 137$ & $0 \cdot 136$ \\
\hline & $15 \cdot 0$ & 0.074 & 0.074 & 0.073 & 0.073 \\
\hline & $20 \cdot 0$ & $0 \cdot 045$ & 0.045 & $0 \cdot 045$ & 0.045 \\
\hline \multirow[t]{6}{*}{1} & 0.0 & 0.869 & 0.857 & $0 \cdot 831$ & 0.806 \\
\hline & 1.0 & 0.654 & 0.645 & 0.629 & 0.613 \\
\hline & 5.0 & $0 \cdot 288$ & 0.285 & $0 \cdot 279$ & 0.274 \\
\hline & $10 \cdot 0$ & 0.128 & 0.127 & 0.124 & 0.122 \\
\hline & $15 \cdot 0$ & 0.070 & 0.070 & 0.069 & 0.068 \\
\hline & $20 \cdot 0$ & 0.043 & $0 \cdot 042$ & 0.042 & $0 \cdot 041$ \\
\hline \multirow[t]{6}{*}{5} & 0.0 & 0.469 & 0.448 & 0.407 & $0 \cdot 369$ \\
\hline & 1.0 & $0 \cdot 350$ & $0 \cdot 336$ & $0 \cdot 308$ & $0 \cdot 282$ \\
\hline & $5 \cdot 0$ & $0 \cdot 155$ & $0 \cdot 150$ & $0 \cdot 140$ & $0 \cdot 130$ \\
\hline & $10 \cdot 0$ & 0.073 & 0.071 & 0.068 & 0.065 \\
\hline & $15 \cdot 0$ & $0 \cdot 046$ & 0.045 & 0.043 & 0.041 \\
\hline & $20 \cdot 0$ & 0.031 & 0.030 & 0.029 & 0.027 \\
\hline \multirow[t]{6}{*}{10} & 0.0 & 0.230 & 0.216 & $0 \cdot 189$ & $0 \cdot 164$ \\
\hline & $1 \cdot 0$ & $0 \cdot 178$ & $0 \cdot 166$ & $0 \cdot 145$ & $0 \cdot 127$ \\
\hline & $5 \cdot 0$ & $0 \cdot 080$ & 0.076 & $0 \cdot 067$ & 0.061 \\
\hline & $10 \cdot 0$ & 0.049 & 0.048 & $0 \cdot 045$ & 0.043 \\
\hline & $15 \cdot 0$ & 0.036 & 0.035 & 0.032 & 0.030 \\
\hline & $20 \cdot 0$ & 0.024 & 0.023 & $0 \cdot 021$ & 0.020 \\
\hline
\end{tabular}

\section{Conclusions}

Water quality concerns are some of the important issues in urban storm sewer system design. While meeting the discharge standards, the system should be cost-effective as well. There are several combinations of urban rainfall drainage systems. This paper examines the effect of installation of retention basins in the system, which actually store some quantities of water for a temporary period before discharge. This retention process reduces the water quantity let out to the recipient water body at a given time, thereby decreasing the organic contaminant load, which helps in meeting discharge standards. Such a system deserves careful attention and sensitive calculations of basin volume, overflow duration and overflow water amount. In this study, a model is developed for a retention basin design. The model is then applied to 
3-year duration rainfall data. It is concluded that such a model is very useful and actually needed for urban storm sewer design. The climatic changes in many parts of the world and the severe floods observed recently, increase the need for models such as the one introduced in this study.

\section{References}

Annen G, Londong D 1960 Vergleichender Betrachtung zur Bemssung von Rückhaltebecken. (Essen, Germany: Techn. Wiss. Mitt. d. Emshergenossenschart) p. 3

Bourgogne P, Chorda J 1995 Optimisation of retention basin decanting. Water Sci. Technol. 32: 101108

Muslu Y 1966 Research into the assessment of design rainfall in urban hydrology: Ph D Thesis, Istanbul Technical University, Istanbul, Turkey

Ordon C J 1974 Volume of storm water retention basins. J. Environ. Eng. Division, ASCE 100: 11651177

Piel C, Perez I, Maytraud T 1999 Three examples of temporary stormwater catchments in dense urban areas: a sustainable development approach. Water Sci. Technol. 39: 25-32

Solmaz B 1982 Analysis of the factors that affect the storage capacity and pollution in urban areas. $\mathrm{Ph} \mathrm{D}$ thesis, Istanbul Technical University, Istanbul, Turkey 